\title{
Exploring the Benefits and Uses of Web Analytics Tools for Non-Transactional Websites
}

\author{
Manya Sleeper \\ Carnegie Mellon University \\ Pittsburgh, PA \\ msleeper@cs.cmu.edu
}

\author{
Sunny Consolvo \\ Google \\ Mountain View, CA \\ sconsolvo@google.com
}

\author{
Jessica Staddon \\ Google \\ Mountain View, CA \\ staddon@google.com
}

\begin{abstract}
Website owners use web analytics tools to better understand their visitors for a range of purposes. However, there is limited understanding of how owners of non-transactional websites use and benefit from web analytics. Through semistructured interviews $(n=18)$ with non-transactional web analytics users we explore these uses and benefits. Participants tend to use web analytics to improve site design, by optimizing site structure, content, or technical specifications. However, participants also use web analytics to understand their audiences without a directed purpose, often for curiosity or entertainment. The design of web analytics tools should account for this full range of functionality.
\end{abstract}

\section{Author Keywords}

web analytics; online; uses and benefits

\section{ACM Classification Keywords}

H.5.m. Information Interfaces and Presentation (e.g. HCI): Miscellaneous

\section{INTRODUCTION}

Website owners use web analytics for "the measurement, collection, analysis and reporting of Internet data for the purposes of understanding and optimizing Web usage" [1]. A 20-something blogging about her outfits might check web analytics to see if anyone from other countries is reading. A small business owner might use a similar tool to try to decide how to change the site's layout to encourage customer retention. A range of web analytics tools facilitate the collection and visualization of website visitor data. However, while literature (e.g., $[11,13])$ offers recommendations for how to use such data, especially for transactional sites that are primarily intended for commercial purposes like advertising or sales, there is currently very limited work on how website owners actually use these tools.

To understand how site owners use and benefit from web analytics tools, and inform the design of such tools, we performed 18 semi-structured interviews with non-transactional

Permission to make digital or hard copies of part or all of this work for personal or classroom use is granted without fee provided that copies are not made or distributed for profit or commercial advantage and that copies bear this notice and the full citation on the first page. Copyrights for third-party components of this work must be honored. For all other uses, contact the owner/author(s). Copyright is held by the author/owner(s).

DIS 2014, June 21-25, 2014, Vancouver, BC, Canada.

ACM 978-1-4503-2902-6/14/06.

http://dx.doi.org/10.1145/2598510.2598555 web analytics users. In line with recommendations offered by practitioner literature, our participants tend to use analytics to improve various aspects of site design, including content and layout, as well as increase traffic and self promote. However, they also tend to use the tools to try to understand their site's audience, for primarily entertainment or curiosity. Web analytics tools could potentially be more usable for users like these if they addressed this full range of needs.

\section{BACKGROUND AND RELATED WORK}

We examine benefits and uses of web analytics for owners of non-transactional sites. These tools (e.g., Google Analytics, Wordpress Stats, StatCounter, Blogger Stats, etc.) facilitate collection and understanding of website visitor data. Many tools allow users to track data like number of visitors (e.g., total, new, returning, unique), visitor technology (e.g, devices, monitor specifications, operating systems, browsers), locations (e.g., country, state, city), network hostnames, search keywords, behavior on the site (e.g., heat maps of clicks, entry and exit pages, popular posts), and referrer links.

Web analytics practitioner literature recommends how web analytics data should be used. Wiggins describes three heuristics for using analytics based on improving site content and structure: evaluating 'branding' by ensuring an "engaging or memorable experience," examining 'usability' by ensuring that visitors can accomplish their tasks, and making sure that content is 'appropriate' and navigation is optimized [13]. Such work focuses on topics like how to track web visitor data to optimize site design, improve customer service or retention, improve purchase behavior, meet business goals through analytics tracking and site improvements (e.g., [6, 2]), as well as generally evaluate website usability [5].

However, there is very limited work on how site owners actually use analytics data. In line with practitioner literature, Phippen et al. use airline case study data to suggest that analytics can be used to understand customer behavior to improve content, design and performance to reduce customer 'drop-outs' [11]. There is no work examining how more general users use web analytics. We intend to provide insights for the design of web analytics tools by addressing this gap.

\section{METHODOLOGY}

We explore uses and benefits that non-transactional website owners derive from web analytics through 18 semi-structured interviews with non-transactional analytics users (Table 1). We recruited participants through a national, US recruiting 
service. We focus on non-transactional users because there is no current literature on how such users use web analytics.

\begin{tabular}{|c|c|c|c|c|c|}
\hline 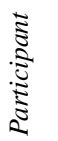 & 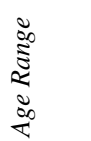 & 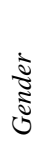 & 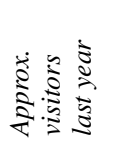 & $\ddot{8}$ & 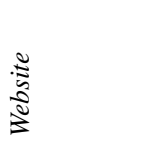 \\
\hline P1 & $31-40$ & M & 82 & Google Analytics & Nature blog \\
\hline P2 & $24-30$ & M & $54(6 \mathrm{mos})$ & Google Analytics & Personal site \\
\hline P3 & $31-40$ & M & $\begin{array}{l}96 \mathrm{~K} \\
\text { (unique) }\end{array}$ & Google Analytics & $\begin{array}{l}\text { Video game } \\
\text { wiki }\end{array}$ \\
\hline P4 & $31-40$ & $\mathrm{~F}$ & $16 \mathrm{~K}$ & Google Analytics & Personal site \\
\hline P5 & $31-40$ & $\mathrm{~F}$ & 1,952 & Google Analytics & Personal site \\
\hline P6 & $41-50$ & M & $91 \mathrm{~K}$ & Google Analytics & $\begin{array}{l}\text { Wife's well- } \\
\text { ness blog }\end{array}$ \\
\hline P7 & $18-23$ & M & 42 (2 wks) & Google Analytics & $\begin{array}{l}\text { Site for non- } \\
\text { profit }\end{array}$ \\
\hline P8 & $18-23$ & $\mathrm{~F}$ & 176 & Blogger Stats & $\begin{array}{l}\text { Personal } \\
\text { blog }\end{array}$ \\
\hline P9 & $24-30$ & M & $\begin{array}{l}3,300 \\
\text { (unique) }\end{array}$ & Google Analytics & $\begin{array}{l}\text { Music/photo } \\
\text { blog }\end{array}$ \\
\hline P10 & $51-60$ & M & $15 \mathrm{~K}$ & StatCounter & $\begin{array}{l}\text { Site for tech } \\
\text { writing/talks }\end{array}$ \\
\hline P11 & $41-50$ & M & 2,220 & Google Analytics & $\begin{array}{l}\text { Film noir } \\
\text { blog }\end{array}$ \\
\hline P12 & $24-30$ & $\mathrm{~F}$ & 8,500 & Wordpress Stats & $\begin{array}{l}\text { Running } \\
\text { blog }\end{array}$ \\
\hline $\mathrm{P} 13$ & $18-23$ & $\mathrm{~F}$ & 7,857 & Wordpress Stats & $\begin{array}{l}\text { Personal } \\
\text { blog }\end{array}$ \\
\hline P14 & $24-30$ & M & $1.5 \mathrm{M}$ & Google Analytics & Travel blog \\
\hline P15 & $31-40$ & $\mathrm{~F}$ & 6,293 & Blogger Stats & $\begin{array}{l}\text { Film review } \\
\text { blog }\end{array}$ \\
\hline P16 & $31-40$ & M & $23 \mathrm{~K}$ & Google Analytics & $\begin{array}{l}\text { State poli- } \\
\text { tics/books } \\
\text { blog }\end{array}$ \\
\hline P17 & $51-60$ & M & $15 \mathrm{~K}$ & StatCounter & $\begin{array}{l}\text { Personal } \\
\text { blog }\end{array}$ \\
\hline P18 & $41-50$ & M & 584 & Google Analytics & $\begin{array}{l}\text { Personal/tech } \\
\text { blog }\end{array}$ \\
\hline
\end{tabular}

Table 1. Interview participant demographics.

We limited participants to people who self-identified as being in charge of maintaining a non-commercial blog or website and using a web analytics tool on the site. To identify nontransactional sites, we specified to participants that "the primary purpose of the site" they maintained should "NOT be to advertise or sell services/items and it shouldn't have been created primarily as part of your job." Potential participants also provided a link to their sites; any whose sites were primarily for selling products or services were not invited to participate.

Most participants were interviewed remotely; two local participants were interviewed in person in Mountain View, CA. Interviews were run in June and July of 2013. One interviewer performed all interviews, which were audio recorded and transcribed. Screen sharing and capture were performed for the remote interviews so participants could demonstrate how they used their tools. Each interview lasted about an hour and participants received a $\$ 100$ gift card.

The interviews were semi-structured. We based the interview methodology on a uses and gratifications approach, which has been used to examine other types of online media and services (e.g., [3, 8]). Question were based on those used by Lindqvist et al. [9]. The participant first described their site. They then described their web analytics uses and benefits.
The interviewer asked the participant to log into their analytics account and walk the interviewer through typical uses. The interviewer also asked probing questions about why the participant used analytics, the benefits of using web analytics, the most useful/interesting/surprising things learned through using analytics, the impacts of use on behavior, and general web analytics habits and use. The interviews were piloted with six additional participants whose results are not reported.

For analysis we first created codes for the uses and benefits of web analytics based on themes from a review of uses and gratifications literature $[3,4,7,10,8,9]$. One researcher then iteratively developed an initial codebook from the data. Two researchers then iterated twice over the codes to develop a final codebook of nine codes. After the codebook was finalized, the second coder coded a random sample of 74 items (Kappa $=0.69 ;>0.60$ is considered "substantial agreement" [12]).

\section{PARTICIPANT DEMOGRAPHICS}

Participants (Table 1) use varied tools, weighted toward Google Analytics. They tend to be tech-savvy, trending toward tech- or media-related professions, likely due to recruitment for participants in charge of maintaining websites. They maintain a range of website types with varied audience sizes, including many types of personal and hobby-related blogs.

\section{RESULTS}

In line with practitioner literature, participants tend to use web analytics to inform site design and improve content, as well as to try to increase traffic and perform technical optimization. However, participants also tend to use analytics in a less directed manner to try to understand their audiences, often for curiosity or entertainment. We also found that the chosen tools did not always meet all participant needs; some participants specifically felt overwhelmed by available data.

\section{Understand audience}

All participants use web analytics to try to understand site audiences without direct use for the data, often for amusement or out of curiosity. They want to know who the visitors are, where they come from, and what they are doing. Participants are often just interested or like to look at the data and do not intend to use it to make site changes. As P3 said: "it's just kind of to keep track and satisfy my curiosity." They tend to look for audience size and traffic patterns, locations, referrers, or behavior on the site (e.g., heat map). P13 described:

"Just to see how much traffic I get with a post. It's just kind of interesting. I think the most interesting is seeing where the views come from it by country. And then a lot of times you'll see that a lot of views are international and you're like oh, I wonder where they - you get that crowd."

Some participants find looking at analytics data entertaining: "It's more like a game to me than it is a very serious pursuit of analytics" (P8) or amusing: "Sometimes it's just amusing see - like I have a search here for airborne toxic legs" (P9).

Some participants also try to use web analytics to see if people from specific companies or organizations, or people they 
met at events, visit their sites (6/18). For example, P2, a student with a personal site, tried to see if contacts from professional meet-ups later visited his site, explaining:

“...we kind of exchange information, I'll kind of-I don't know, I might check the next day to see if someone, you know, from Colorado checked it out."

Others check for visitors from certain companies, typically during job searches or in connection with content on their site about a particular company, as P5 described:

"I wrote a couple of articles that had highlighted or showcased different technology companies in the article. And so then I would see that that company itself was looking over or I could assume. If I couldn't see their name I could see their location and usually I could tell that they were like spreading the word of mouth of the article."

In general, participants with small or medium size sites (i.e., $<10 \mathrm{~K}$ visitors/year) were more likely to try to use web analytics to try to see if specific people, or people from specific companies visited their sites. This may have been due to many of these sites being personal or resume-related.

\section{Increase traffic}

Although participants are non-transactional site owners, many (15/18) want to increase page views. For example, several participants maintain blogs they eventually hope may transition to commercial sites. Other participants just like to increase the popularity of the content. Participants mentioned search engine optimization, like adjusting tags and keywords based on web analytics data to try to improve search rankings. They also try to determine the best time to post content to maximize visitors, like P4: "Which day should I be posting? Which kind of post is it spiking on? Who mentioned it? Did it get shared on Twitter?" Participants, like P9, also try to improve how they promote their site content:

“...Like how would I go about promoting this in a better way? How can I gauge what's working and what isn't? It's less about the content, more about how I might explode that to specifically individuals or social networks."

\section{Improve site design}

Many participants (13/18) use web analytics to try to improve their site design. Some participants use data like keywords, locations, or popular posts to try to understand popular content and how to attract more visitors by changing the content. P16, a political blogger, explained how he uses web analytics to understand popular topics for his writing:

“...I've learned how little people care about serious public policy and how much more they'd rather read salacious stuff. If I ever get something with Kim Kardashian in it, oh my gosh, people go crazy."

Similarly, P5 targets his articles to better attract audiences:

"So if I know that a lot of my articles are popular in Salt Lake City or somewhere like that then I usually try to figure out what element of the writing or what keywords are being utilized to attract that type of audience. And then if there's a way for me to optimize that and use it to my benefit for, say, another article then I can figure out how to use keywords to attract those folks again."

Participants also try to optimize site navigation or structure so users can better reach content. For example, P4 described:

“...I picked this template, I got rid of the side bar it's cause people were constantly clicking crap over here, and they weren't doing the stuff I wanted them to do. So, I find that I'm stripping stuff out, just kind of based on the heat map."

Several participants (11/18) also use web analytics to design their sites for users' device specifications, or they use system statistics, like site speed or page load times for technical troubleshooting. They use data like visitors' browsers, operating systems, or devices:

"If I see a particular version of Firefox or, you know, and some things may look different in a version, I'll definitely go and research and make sure that browser is okay" (P2).

\section{Ad management and self-promotion}

Although not a primary focus, a few participants (3/18) use web analytics to track ads or decide on placement. Some participants casually track ads, for example, to see if the revenue pays for the site's server, or use analytics to decide where to place ads on their sites. A few participants (3/18) also use web analytics data as self-promotional credentials. For example, P14, a travel blogger with a large audience, uses his data to prove how popular his blog is to get free trips.

\section{Other behaviors}

We saw two other trends. First, the tools provided data that participants did not use. Participants (9/18) described data they know exists but do not use, either because of lack of understanding or because they think it is not applicable. For example, several participants described ad- or business-related metrics, like ad performance or visitor conversion rates, that they believe can be tracked but that they either do not understand or do not think apply to their sites. P7 explained:

"I think if we were running sort of like advertising campaigns or assigned product it would be easier to track those things as well but since we're not those aren't too big of a deal."

Several participants also described metrics they ignore. P14, for example, never looks at language data, because "everyone that visits my site's gonna mostly speak English.” A few participants also described choosing to ignore keyword data when deciding on site content.

Most participants (17/18) also described using web analytics because the tools provide data easily or because of low barriers to installation, for example because of familiarity, automatic installation, brand familiarity, or because it was free. Owners of smaller- and medium-sized sites (i.e., $<20 \mathrm{~K}$ visitors/year) were more likely to use free or convenient tools.

\section{LIMITATIONS}

This study is exploratory. We limited interviews to US website owners, which reduces the generalizability. We also rely on self-reported data. Such data is unconfirmed and impacted 
by biases, such as recency and social desirability. Our results may be skewed toward more memorable and socially desirable uses and should be verified through experimental and observational studies. However, this study provides initial insights into how web analytics are used by non-transactional users, which may serve as a basis for future design.

\section{DISCUSSION}

In line with prior work on web analytics for transactional websites (e.g., $[13,11])$ participants use web analytics for site design improvements, including adjustments to site and content, but also use the tools to understand their audiences for more personal entertainment or emotional benefits.

Many participants run hobby or passion-project websites. Their site optimization goals range from wanting to build a visitor base to eventually transition to a commercial project to wanting to generate more interest for a favorite project to wanting to make sure that the site is still running. We also found that participants tend to use web analytics for entertainment or emotional benefits, and, in some cases to provide affirmation. P11 described "All I got is analytics. That's what tells me whether or not my efforts are reaching anyone."

Many web analytics tools track a wide range of visitor data that, according to practitioner literature, can be used to improve sites. However, our participants often only use a subset of available data, sometimes finding the full range of options unusable and overwhelming. As P14 put it: "There's more data here than I could possibly ever need." Instead, some participants tended to want to be able to more easily get to the data they wanted. P17 described: "Really with a personal blog I need to drill down two or three levels in order to get all of the source data. That's silly to me."

Web analytics tools often primarily support more transactional goals, for example sale generation or customer retention. The mismatch between some non-transactional participant goals and interests and the primary functionality of many analytics tools sometimes led participants to develop workflows in which they went through data they found interesting and avoided parts of the tool they felt were not intended for them. One participant described "I've usually probably used it most as a hammer as opposed to as a fine chisel" (P11). Some participants felt frustrated or like they were missing the full potential, and some wanted to better understand how to use available functionality. P18 explained: "I wish it was easier for me to figure out the other interesting things."

The design of web analytics tools, especially free tools commonly used by non-transactional users, should account for the full range of potential user goals. For example, they could also provide instructions and short-cuts tailored to nontransactional users for different types of uses.

\section{CONCLUSION}

Participants tend to use analytics to understand their audiences, often for curiosity or entertainment, as well as for more site-design oriented tasks like increasing traffic and optimizing content. Web analytics data was also sometimes used to manage ads, as self-promotional credentials, and to perform technical troubleshooting and optimization. This full range of uses should be accounted for in designing analytics tools.

\section{ACKNOWLEDGMENTS}

This work benefited from many peoples' assistance, including: Larkin Brown, Nicholas Davis, Aleksandra Korolova, Jennifer Marlow, Justin Owens, Vasyl Pihur, and Rob Reeder.

\section{REFERENCES}

1. Web analytics definitions. Web Analytics Association, http:

//www . digitalanalyticsassociation.org/Files/ PDF_standards/WebAnalyticsDefinitions.pdf, 2008.

2. Booth, D., and Jansen, B. J. A review of methodologies for analyzing websites. Handbook of Research on Web Log Analysis. Information Science Reference (2009), 143-164.

3. Bumgarner, B. A. You have been poked: Exploring the uses and gratifications of Facebook among emerging adults. First Monday 12, 11 (2007).

4. December, J. Units of analysis for internet communication. J. of Computer-Mediated Comm. 1, 4 (1996).

5. Hasan, L., Morris, A., and Probets, S. Using google analytics to evaluate the usability of e-commerce sites. In Human Centered Design. Springer, 2009, 697-706.

6. Jansen, B. J. Understanding user-web interactions via web analytics. Synthesis Lectures on Information Concepts, Retrieval, and Services 1, 1 (2009), 1-102.

7. Joinson, A. N. Looking at, looking up or keeping up with people?: Motives and use of Facebook. In Proc. CHI, ACM (2008), 1027-1036.

8. LaRose, R., and Eastin, M. S. A social cognitive theory of internet uses and gratifications: Toward a new model of media attendance. J. of Broadcasting \& Elect. Media 48, 3 (2004), 358-377.

9. Lindqvist, J., Cranshaw, J., Wiese, J., Hong, J., and Zimmerman, J. I'm the mayor of my house: examining why people use foursquare-a social-driven location sharing application. In Proc. CHI, ACM (2011), 2409-2418.

10. Park, N., Kee, K. F., and Valenzuela, S. Being immersed in social networking environment: Facebook groups, uses and gratifications, and social outcomes. CyberPsych. \& Beh. 12, 6 (2009), 729-733.

11. Phippen, A., Sheppard, L., and Furnell, S. A practical evaluation of web analytics. Internet Research 14, 4 (2004), 284-293.

12. Viera, A. J., Garrett, J. M., et al. Understanding interobserver agreement: The kappa statistic. Fam. Med. 37, 5 (2005), 360-363.

13. Wiggins, A. Information architecture: Data-driven design: Using web analytics to validate heuristics system. Bulletin of the Am. Soc. for Info. Sci. and Tech. 33, 5 (2007), 20-24. 